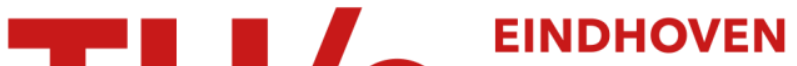 UNIVERSITY OF TECHNOLOGY
}

\section{Stakeholder Perspectives on Design Interventions in Dementia Care}

\section{Citation for published version (APA):}

Houben, M., Brankaert, R., \& Wouters, E. (2020). Stakeholder Perspectives on Design Interventions in Dementia Care. In Companion Publication of the 2020 ACM on Designing Interactive Systems Conference (pp. 43-47). Association for Computing Machinery, Inc. https://doi.org/10.1145/3393914.3395868

DOI:

10.1145/3393914.3395868

Document status and date:

Published: 01/07/2020

\section{Document Version:}

Typeset version in publisher's lay-out, without final page, issue and volume numbers

\section{Please check the document version of this publication:}

- A submitted manuscript is the version of the article upon submission and before peer-review. There can be important differences between the submitted version and the official published version of record. People interested in the research are advised to contact the author for the final version of the publication, or visit the $\mathrm{DOI}$ to the publisher's website.

- The final author version and the galley proof are versions of the publication after peer review.

- The final published version features the final layout of the paper including the volume, issue and page numbers.

Link to publication

\section{General rights}

Copyright and moral rights for the publications made accessible in the public portal are retained by the authors and/or other copyright owners and it is a condition of accessing publications that users recognise and abide by the legal requirements associated with these rights.

- Users may download and print one copy of any publication from the public portal for the purpose of private study or research.

- You may not further distribute the material or use it for any profit-making activity or commercial gain

- You may freely distribute the URL identifying the publication in the public portal.

If the publication is distributed under the terms of Article $25 \mathrm{fa}$ of the Dutch Copyright Act, indicated by the "Taverne" license above, please follow below link for the End User Agreement:

www.tue.nl/taverne

Take down policy

If you believe that this document breaches copyright please contact us at:

openaccess@tue.nl

providing details and we will investigate your claim. 


\section{Stakeholder Perspectives on Design Interventions in Dementia Care}

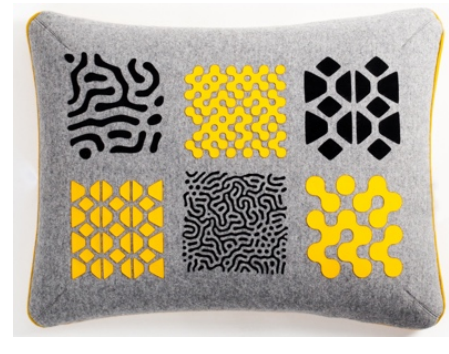

Figure 1: Vita is an interactive cushion for people with advanced dementia to play audio content, such as music or everyday sounds. Vita serves as a design intervention in dementia care facilities to support social contact.

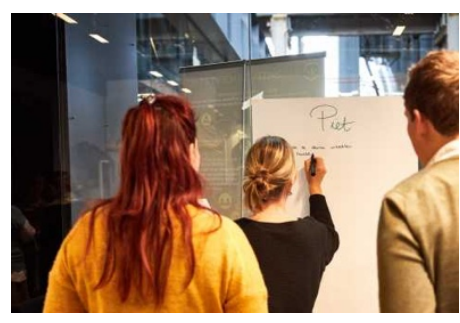

Figure 2: In two workshops, stakeholders in dementia care discussed the requirements for implementing Vita into everyday care.

\section{Maarten Houben}

Industrial Design, Eindhoven University of Technology

m.houben1@tue.nl

\section{Rens Brankaert}

Industrial Design, Eindhoven

University of Technology

\& Fontys University of Applied

Sciences

r.g.a.brankaert@tue.nl

\section{Eveline Wouters}

Fontys University of Applied Sciences \& Tranzo, School of Social and Behavioral Sciences, Tilburg University

e.wouters@fontys.nl

Permission to make digital or hard copies of part or all of this work for personal or classroom use is granted without fee provided that copies are not made or distributed for profit or commercial advantage and that copies bear this notice and the full citation on the first page. Copyrights for thirdparty components of this work must be honored. For all other uses, contact the Owner/Author.

DIS '20 Companion, July 6-10, 2020, Eindhoven, Netherlands (C) 2020 Copyright is held by the owner/author(s)

ACM ISBN 978-1-4503-7987-8/20/07.

https://doi.org/10.1145/3393914.3395868

\begin{abstract}
Research in design and HCI is investigating the role of design interventions in adding value to the quality of life of people with dementia. However, the sustainable use of design interventions in care environments remains challenging due to the complex values and needs of all involved stakeholders. In this paper, we present the results of two workshops with stakeholders from practice, academia, and policy organizations in dementia care, which revealed initial insights into the requirements for implementing design interventions in care facilities. In total, 21 participants explored the criteria to implement Vita, an interactive sound cushion in a dementia care home from the perspective of an entrepreneur, a relative, and a professional caregiver. The workshop outcomes indicate that sustainable design interventions in healthcare settings need to be: 1) directly available in the care space; 2 ) stimulated and supported by care organizations; and 3) come with clear information and personal guidance.
\end{abstract}

\section{Author Keywords}

Care practice; Dementia; Design interventions; Healthcare; Stakeholder.

\section{CSS Concepts}

-Human-centered computing Accessibility $\sim$ Accessibility technologies 


\begin{tabular}{l|l} 
Profession participants & $\#$ \\
\hline Entrepreneur & 1 \\
Care manager & 3 \\
Professional caregiver & 6 \\
Researcher & 1 \\
Student & 4 \\
Activity supervisor & 2 \\
Policymaker & 3 \\
Unknown & 1
\end{tabular}

Table 1: The participants were from practice, academia, and policy organizations.

\begin{tabular}{l|l|l} 
Persona & WS 1 & WS 2 \\
\hline Ellen & $P 1-3$ & $P 10-13$ \\
John & $P 4-6$ & $P 14-17$ \\
Pete & $P 7-9$ & $P 18-21$
\end{tabular}

Table 2: All participants were assigned to a group and persona.

\section{John (Husband)}

John (86) has been living alone since his wife Mia moved to a care home three years ago due to dementia. Mia has not been able to talk well for six months. It is very difficult for John to get in touch with her when he comes to visit her. John used Vita once in a trial period with Mia. Afterwards, he never used it again during his visits.

Figure 3: John's wife has dementia and he can use Vita to seek contact with her.

\section{Introduction}

Designers and researchers in $\mathrm{HCI}$ are increasingly investigating the role of technology in dementia care to support meaningful and socially engaging activities, such as music sessions, reminiscence activities, and art therapy [8]. Within this body of work, research has demonstrated the potential of multimodal design interventions in evoking meaningful responses from and with people with dementia $[3,4,9]$. However, the long-term implementation of these design interventions in dementia care practice remains challenging and underinvestigated. In addition to exploring design modalities and their beneficial effects on people with dementia, designers also need to consider the values and needs of stakeholders in order to achieve a sustainable implementation [2]. These stakeholders mainly involve caregivers who support the use of design interventions [5], relatives who want to engage with the person with dementia [6], and entrepreneurs who take the product to market [1].

This paper presents the outcomes of two workshops with stakeholders in dementia care to explore their perspectives on the sustainable use of Vita, a design intervention for people with dementia. Vita is an interactive cushion with six textile touchpads that can play everyday sounds and music (see Figure 1). In the workshops, we first demonstrated Vita and shared insights from our field study [5]. Next, we divided the participants into three groups, each representing a specific pre-selected stakeholder: entrepreneur, healthcare professional, or relative. We asked each group to identify key values and requirements for the assigned stakeholder (see Figure 2). Lastly, the groups presented their outcomes to each other during a final discussion. The outcomes of the workshops provide initial insights on how design interventions in dementia care should be accessible and available to use, stimulated and facilitated by the care organization, and come with personal guidance and information on the benefits and added value. These insights inform and motivate future research on the implementation of design interventions, such as Vita, in dementia care.

\section{Vita: Interactive Sound Cushion}

Vita (see Figure 1) is an interactive cushion that plays music or other forms of audio content [5]. People with dementia can play and listen to different audio recordings by touching the textile touchpads. Vita is specifically designed to be used together with relatives or caregivers and offers immediate access to generic audio content, such as nature sounds or popular songs. Caregivers are able to upload personal audio to Vita, such as music or voice recordings from relatives by using the mobile app. Our field study on the deployment of Vita in two care facilities revealed how everyday sounds provided by Vita cued meaningful conversations, discovery and playfulness, and verbal and nonverbal communication in everyday care [5].

\section{Workshops with Stakeholders}

We adopted a participatory approach [11] to explore and highlight the opinions and views of relevant stakeholders with practical expertise in dementia care. We organized two workshops at a conference on healthcare innovations for 21 attendees from care practice, education, or companies (see Table 1). Nine participants took part in the first workshop and 12 participants in the second workshop (see Table 2), with each workshop lasting one hour. All participants were given a persona, which is a fictive stakeholder with specific needs and values to help the participants relate 
Ellen (Professional caregiver)

Ellen (32) has been working as a caregiver for nine years in a psychogeriatric department at a care facility. Ellen enjoys doing her job but one of the more difficult things in her work is making contact with residents who cannot communicate well through speech. Eighteen months ago, she saw how Vita was being used in a pilot study at another department. But for her, it is not possible to use Vita on a regular basis.

Figure 4: Ellen works in a care facility but struggles to use Vita.

\section{Pete (Entrepreneur)}

Pete (41) is the owner of a company of 20 employees, specialized in healthcare innovations. Pete wants to market VITA as a product to expand his business and to become a national player in the field of healthcare innovations. Pete struggles with the implementation of VITA in the healthcare sector, and what service he should provide for the product to have the highest possible success.

Figure 5: Pete wants to put Vita on the market. to them [10]. The participants received a description of their assigned persona, including name, profession, age, and experience with Vita. We provided three personas: John, an informal caregiver who has a wife with dementia (see Figure 3); Ellen, a professional caregiver working at a care facility for people with dementia (see Figure 4); and Pete, the owner of the fictitious company that will market Vita (see Figure 5).

The workshop started with an introduction round, where the participants stated their names and professions (see Table 1). Next, we introduced the participants to Vita and shared the insights from our field study of the deployment of Vita in a dementia care facility [5] during a short presentation.

After the introduction, participants were randomly divided into three groups. Each group was assigned a specific persona (John, Ellen, or Pete). The participants were asked to discuss in their group what was needed for their persona to guarantee the sustainable use of Vita in long-term dementia care. Each group was given a flipchart (see Figure 6) to write down requirements and considerations for their persona.

Finally, each group was asked to share their results of the in-group discussion with the other participants during the plenary discussion (see Figure 7). During this discussion, there was also room for questions or remarks from participants of other groups. The plenary discussion was audio-recorded and transcribed verbatim. The transcripts and notes written on the flipchart were analyzed by classifying statements using codes for reoccurring concepts. New sub-codes were developed based on patterns within each concept and relevance to the research question.

\section{Results}

Availability and Ease of Use

One group expressed their thoughts on how Vita needs to be available and directly deployable in everyday care activities. P14 stated how Vita should blend in the existing care environment to enable the direct availability for relatives: "What we found especially important is the ease of taking the cushion [...] it should serve as a decoration, e.g., on the sofa [...] so you can just take it and that it is there." Two groups stated how Vita should therefore offer access to general content so you can directly use it without having to deal with the settings, as summarized by P14: "you should be able to set it up easily [...] that those general sounds are already included". Over time, relatives can then provide "personal audio content when everyone is used to working with the device" [P1]

Personal Approach in Guidance and Information Three groups stressed the importance of guidance and information to enable the sustainable use of Vita "both in the organization as in meetings with family members, care workers, and volunteers" [P7]. For relatives, instructions should be provided on how to use Vita: "If I were a family member, I would still like some more explanation on how and when I can use it?" [P4]. Guidance for relatives should also include success stories and potential beneficial outcomes to illustrate "that it is not just for fun [...] and that it does have a clear added value" [P14]. To share these stories of success, the information and guidance should not only be provided on paper but also during moments of personal contact with experts, caregivers, or other users. P4 mentioned how the care facility can organize a "family night" where "experienced users explain how Vita affected the family members, to make them 


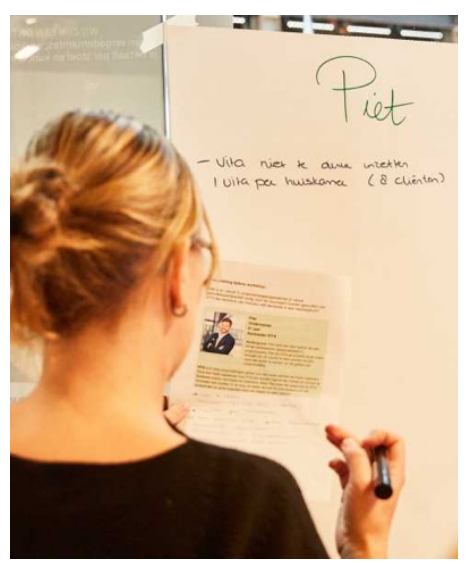

Figure 6: Participants working in groups, discussing the specific needs and considerations of their assigned persona.

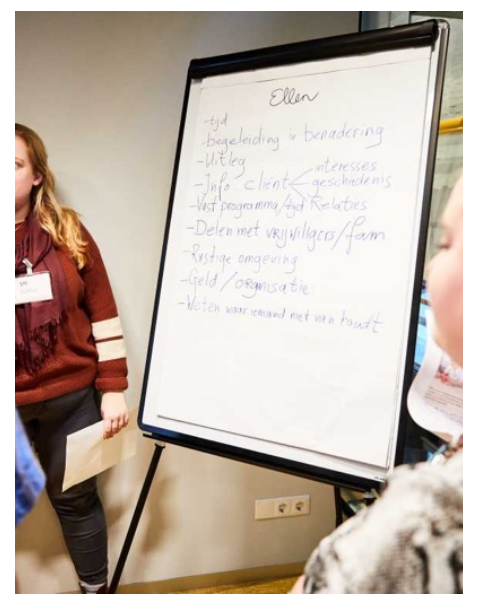

Figure 7: Participants sharing their insights with other groups during the plenary discussion. enthusiastic in another way than to hand over a flyer." For the professional caregivers, clear guidance is needed in how to facilitate sessions with Vita and persons with dementia: "Ellen also likes guidance, how to approach it, how to work with the cushion" [P10]. It is also essential for caregivers to share the specific benefits and added value of using Vita as it: "should be endorsed by the entire team, that they should be really enthusiastic" [P1]. An approachable contact person can guide and stimulate caregivers in using Vita, answer potential questions, and provide technical support, as P5 summarized: "if you want the product to succeed, you must ensure that you are there or available."

Facilitated and Stimulated by Care Organizations Participants expressed how the care organization should facilitate and stimulate the use of Vita, as it should not be used on the spot, but on "set times and activities [...] in a quiet environment, that people can receive the message and positive sounds from the cushion" [P10]. From the perspective of the professional caregiver, sufficient time and resources are needed from the organization for caregivers to use Vita purposefully during scheduled activities. P3 explains how caregivers need "to take their time to sit down with the person, and not that after five minutes if someone gets emotional, [the caregiver says] 'oh yes but now I have to get back to work!" Other stakeholders could also be assigned to use Vita to address the lack of time and resources in care facilities: "because Ellen has primary care duties, and relatives and volunteers have extra time" [P11]. Involving relatives in using Vita can be a way for care facilities to offer support, as relatives often have trouble coping with the loss of contact, as experienced by P14: "sometimes the family finds it very difficult when a family member's dementia is progressing, how to cope with it and how to seek interaction. They often ask advice from me, so it is important that the care organization can recommend and explain the benefits of Vita in supporting contact."

\section{Stakeholders Perspectives in Future Work}

The workshop outcomes provide initial insight into the views and requirements of relevant stakeholders to implement design interventions in care practice. Design interventions should be ready-to-use and blend in with the existing care environments to prevent potential barriers in use and facilitate 'opportunistic' activities that evoke pleasure and immediately create a form of social connection with the person with dementia in the care space [7]. When deploying design interventions in care settings, providing clear information, instructions, and guidance could motivate and stimulate use during everyday activities. Here, a personal approach with other users sharing their experience can support relatives, who often long to share and receive advice from other informal caregivers [6]. The care organization can support professional caregivers by providing time (e.g., scheduled activities) and resources (e.g., volunteers or relatives) to support everyday use and increase the visibility of the design intervention within the organization. In conclusion, we argue that designers should consider the sustainability and challenges related to the long-term implementation of design interventions in care settings, in addition to exploring initial in-context effects. With this paper, we aim to encourage future design research to incorporate perspectives and values of key stakeholders, such as care practitioners, entrepreneurs, and relatives, to further investigate the successful and sustainable use of design interventions in healthcare settings. 


\section{References}

[1] Rens Brankaert and Elke den Ouden. 2017. The design-driven living lab: a new approach to exploring solutions to complex societal challenges. Technol. Innov. Manag. Rev. 7, 1, 44-51.

[2] Rens Brankaert, Elke den Ouden, and Aarnout Brombacher. 2015. Innovate dementia: the development of a living lab protocol to evaluate interventions in context. info 17, 4, 40-52. DOI:https://doi.org/10.1108/info-01-2015-0010

[3] Yuan Feng, Suihuai Yu, Dirk van de Mortel, Emilia Barakova, Jun Hu, and Matthias Rauterberg. 2019. LiveNature: Ambient Display and Social RobotFacilitated Multi-Sensory Engagement for People with Dementia. In Proceedings of the 2019 on Designing Interactive Systems Conference - DIS '19, ACM Press, New York, New York, USA, 13211333.

DOI:https://doi.org/10.1145/3322276.3322331

[4] James Hodge, Kyle Montague, Sandra Hastings and Kellie Morrissey. 2019. Exploring Media Capture of Meaningful Experiences to Support Families Living with Dementia. In Proceedings of the 2019 CHI Conference on Human Factors in Computing Systems - CHI '19, ACM Press, New York, New York, USA, 1-14.

DOI:https://doi.org/10.1145/3290605.3300653

[5] Maarten Houben, Rens Brankaert, Saskia Bakker, Gail Kenning, Inge Bongers, and Berry Eggen. 2020. The Role of Everyday Sounds in Advanced Dementia Care. In Proceedings of the 2020 ACM Conference on Human Factors in Computing Systems - CHI '20, ACM Press, New York, New York, USA, Paper 450, 1-14.

DOI:https://doi.org/10.1145/3313831.3376577

[6] Kiel Long, Lyndsey Bakewell, Roisin McNaney, Konstantina Vasileiou, Mark Atkinson, Manuela Barreto, Julie Barnett, Michael Wilson, Shaun Lawson, and John Vines. 2017. Connecting Those
That Care: Designing for Transitioning, Talking, Belonging and Escaping. In Proceedings of the 2017 CHI Conference on Human Factors in

Computing Systems - CHI '17, ACM Press, New York, New York, USA, 1339-1351.

DOI:https://doi.org/10.1145/3025453.3025715

[7] Kellie Morrissey and John McCarthy. 2015. Creative and Opportunistic Use of Everyday Music Technologies in a Dementia Care Unit. In Proceedings of the 2015 ACM SIGCHI Conference on Creativity and Cognition - C\&C '15, ACM Press, New York, New York, USA, 295-298.

DOI:https://doi.org/10.1145/2757226.2757228

[8] Kellie Morrissey, John McCarthy, and Nadia Pantidi. 2017. The Value of Experience-Centred Design Approaches in Dementia Research Contexts. In Proceedings of the 2017 CHI Conference on Human Factors in Computing Systems (CHI '17), ACM Press, New York, New York, USA, 1326-1338. DOI:https://doi.org/10.1145/3025453.3025527

[9] Kellie Morrissey, Gavin Wood, David Green, Nadia Pantidi, and John McCarthy. 2016. 'I'm a rambler, I'm a gambler, I'm a long way from home': The Place of Props, Music, and Design in Dementia Care. In Proceedings of the 2016 ACM Conference on Designing Interactive Systems - DIS '16, ACM Press, New York, New York, USA, 1008-1020. DOI:https://doi.org/10.1145/2901790.2901798

[10]John Pruitt and Jonathan Grudin. 2003. Personas: Practice and Theory. In Proceedings of the 2003 Conference on Designing for User Experiences (DUX '03), Association for Computing Machinery, New York, NY, USA, 1-15. DOI:https://doi.org/10.1145/997078.997089

[11]Elizabeth B.-N. Sanders and Pieter Jan Stappers. 2008. Co-creation and the new landscapes of design. CoDesign 4, 1, 5-18. DOI:https://doi.org/10.1080/15710880701875068 